\title{
The Influence of Psychological Mechanisms on Intergroup Adaptation as a Resource for Corporate Management and Organizational Changes
}

\author{
Aleksandr Bulgacov ${ }^{1}$, Darya Belinskaya ${ }^{2}$, Vasilii Fedorovich ${ }^{1}$ and Ivanna Abrosimova ${ }^{2, *}$ \\ ${ }^{1}$ Moscow State Regional University, Moscow, Russia, \\ ${ }^{2}$ Moscow State University of Civil Engineering, Yaroslavskoe shosse, 26, Moscow, 129337, Russia
}

\begin{abstract}
In the article, the author provides the findings of the empiric study, involving the employees of construction companies, with account for their diverse social statuses. Top executives, directors of departments, and engineers participated in the research project, covered by the article. One hundred and forty employees of six construction companies were involved in the empiric study. The project comprises quantitative and qualitative correlation of management situations, based on the methodology, developed by D. Snowden; contributions made by the psychological mechanisms of intergroup adaptation, as well as the resolution of management situations. The findings have proven that by getting adjusted to versatile management situations, group members alter the motivation potential of their groups by urging other groups, interacting with theirs, to get adjusted to the new environment of social interaction. Therefore, the difference in the motivation potentials of interacting groups may cause the resonance, leading to constructive solutions.
\end{abstract}

\section{Introduction}

The present-day business environment forces each executive to assume a new style of management, that is, management through situation modeling, whereby a top executive becomes a universal manipulator, capable of working with the object as a whole and developing unique instruments for the resolution of unexpected problems. [1]Decisions, made contrary to the regularities of organizational psychology and involving the "psychological mechanisms", produce an adverse impact on such phenomena, as mutual confidence in the business environment, decision making by groups in the situation of uncertainty, implementation of decisions and their influence on the consequences of joint actions. We believe that the study of intergroup interactions and the influence, produced by problematic situations,

\footnotetext{
${ }^{*}$ Corresponding author: docent.abrosimova@mail.ru
} 
requires the involvement of the socio-cognitive approach, or the basic category of the "corporate intergroup adaptation". [2] Intergroup interactions are capable of unlocking the nature of intergroup processes and act as the explanatory principle, underlying the behaviour of a professional group, on the one hand, and determining the course of actions and performance, on the other hand. [1]

The scope of research into this methodology, applicable to consistent patterns of intergroup adaptation, and into the technology for its optimization covers the validation of concepts, underlying the $\mathrm{p}$ sychological mechanisms of intergroup adaptation, including the (1) intergroup inadaptability, (2) organizational identification, and (3) joint activity. The mechanisms, belonging to different semantic fields, apply to each item of work, performed by the whole organization. A. Bulgakov looked into the problem of intergroup adaptation at educational institutions [2]; E. Mitasova studied intergroup adaptation at healthcare centres [3]; Aksenovskaya did research on intergroup adaptation atinstitutions of construction economics. [4]Psychological mechanisms (PM) demonstrate their efficiency, if applied to the explanation of the reasons for intergroup adaptation, to the projection of its pattern and pace, and to the development of recommendations aimed at the optimization of corporate personnel management. The application of the notion "psychological mechanism" in the course of the socio-cognitive analysis of intergroup adaptation (1) facilitates the research into the essence, ideas and paradigms of organizational groups, having different corporate statuses, and (2) makes them less congruent. A relevant problem of contemporary Russian construction companies consists in their inability to build confidence between executives and employees, free from any direct manipulation. [5]

The article contains the findings of the socio-cognitive research into the role of the structure of psychological mechanisms of intergroup adaptation in corporate management and development. [2] The research also contemplates the pilot testing of the methodology for the targeted employment of "psychological mechanisms" of intergroup adaptation aimed at the identification of Cynefin cognitive areas. [6] Directors of departments and their subordinates participated in the research project. The project's theoretical background consists in the analysis of the complementary adjustment of the theory of knowledge management, organizational applications of the theory of complex systems, as understood by D. Snowden (an expert in knowledge management and the director of the centre specializing in the corporate consulting on knowledge management).

\section{Objectives and results}

The wholesome set of multilevel psychological mechanisms for corporate intergroup adaptation can be correlated with the situations, influencing the resolution of management problems in the framework of the Cynefin platform (given that attention is driven to order, regularity, complexity, chaos and uncertainty). This procedure facilitates transition from the descriptive to the forecasting nature of management situations. The corporate development pattern can be identified through the employment of specific values of psychological mechanisms for intergroup adaptation, namely, the number of degrees of freedom in terms of the algebra of event (the Boolean algebra)[7], as well as the trajectories and paces, measured by the performance of the wholesome set of psychological mechanisms of intergroup adaptation by the criteria of adaptive, organizational, and motivational potentials of interacting groups.

An organizational psychologist should take advantage of his/her socio-cognitive skills to solve production problems and to explain the performance of psychological mechanisms to a construction executive, having identified intergroup interaction regularities with ac- 
count for the social status. The mission of an organizational psychologist is (1) to draw attention to the effects, causing psychological transformations, which set the stage for naturally determined actions, (2) to explain the cause and effect of actions taken by the employees, (3) to develop the programme for the development of personal resources, inclusive of psychological maintenance, training and personnel development courses.

Our project has illustrated the capacity of the socio-cognitive analysis, if applied to the potential of the corporate development of construction companies with account for the intergroup adaptation concept.

The intergroup adaptation of employees, having different statuses within construction companies, serves as the scope of research. The respondents are the top executives, directors of departments, and engineers. [8] The subject of research consists in the interrelation between the structure of psychological mechanisms of intergroup adaptation and the management situations, broken down by the Cynefin platform.

Sampling properties. 140 employees of six construction companies took part in our empiric research project. $82 \%$ of them hold degrees, issued by higher education institutions; $42 \%$ of them are males, and $58 \%$ - females, who are $20-55$ years old. The average age gap between the members of high and low status groups varies from two to eight years.

The organizations were exposed to comparison through: (1) the adjustment of their samplings with account for the social and demographic values, aimed at the identification of uncontrollable variables, associated with these values; (2) the study of the employees' performance. The expert evaluation of the employees' performance was made by the immediate managers of the respondents on the basis of the questionnaire.

The procedure for the expert evaluation of corporate development patterns and executive decisions was performed with the help of the Cynefin platform. It is noteworthy that, in the course of the conversation, each respondent identified the position of his/her company by speaking about the opportunities associated with the projected development of his/her resource-related and management decisions. They also identified the extent of their responsibility.

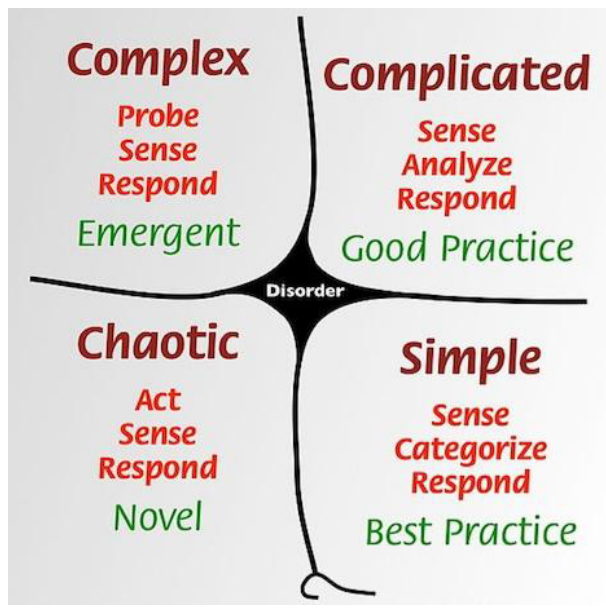

Fig. 1. The Cynefin platform, developed by D. Snowden.

The classification of corporate areas, identified by D. Snowden, is based on the specific understanding of a problem through its perception, and it influences the choice of management decisions. D. Snowden believes that there are five management situations. Cynefin areas have curved borders, and, according to D. Snowden, their visual presentation serves 
to demonstrate the difference between Cynefin and other four-cell matrixes, widely spread in psychology and business sciences. The essence of $\mathrm{X}$ and $\mathrm{Y}$ axes is not important here (see Fig. 1).

Our methodology, developed for the examination of employees, having different corporate statuses, is built around the system of approved criteria, values and methodologies (Fig. 2).

The findings of the diagnostic research, based on the psychological methodology, developed by K.Rogersand R.Diamond and entitled "Diagnosticsofsocio-psychological adaptation", are built around the results and analysis of our experiment. [9] Our research has demonstrated that the respondents, belonging to interacting groups, get well adapted to their professional teams; they feel comfortable and they do not want to change their professional activities. The projection of conflict situations between the groups, having different statuses, is optimal, as these situations are perceived by the groups in the same way.

For example, low-status engineers get $78 \%$ in Adaptation, while high-status directors of departments get $81 \%$ in it. Low-status employees get $40 \%$ in Self-perception, while highstatus employees get $35 \%$ in it. Engineers get $68 \%$ in Perception of Others, while directors of departments get $79 \%$ in it. Engineers get $64 \%$ in Emotional comfort, while directors of departments get $59 \%$ in it. As for Internality, engineers get $43 \%$, while directors of departments $-65 \%$. As for Willingness to Dominate, engineers get $49 \%$, directors of departments $-33 \%$. As for Escapism, engineers get $22 \%$, and directors $-23 \%$.

The next stage of research consisted in the identification of motivators for our respondents. Our research methodology is based on the system of approved criteria, values and methodologies. [10] Methods of mathematical and statistical analyses were used to process the findings. The group of engineers, selected as the respondents, identified the following three dominant factors: (1) the need for a high salary; the need for material remuneration; (2) the need for good working conditions and comfortable environment; (3) the need to maintain ongoing reliable relations. They demonstrate a low level of motivation in respect of the group objectives; they tend to have a low need for setting and attaining complex objectives. Engineers do not need any changes or stimulations; they do not try to avoid mundanity.

As for the motivation profile of directors of departments, employed with construction companies, the top positions are occupied by material incentives and the need for a comfortable environment. The bottom positions are taken by the need for power and the unwillingness to develop willpower. These findings have proven that the values of motivators make no influence on the generation of conflicts.

After having analyzed the findings in the process of the diagnostic study, we performed a statistical verification of discrepancies in the Student's t-test to learn that the groups, having different social statuses, only differedin the motivator that read as the need to be respected by others. Other motivators had similar values.

The motivation potential, demonstrated by the groups, produces impact on the role of the regulator of the group adaptation. Therefore, there is a need to take account of the combination of positive and negative motivation factors at construction companies. Each respondent changed his/her motivation potential, while getting adjusted to the new environment in a group.

The focus of psychological mechanisms complies with corporate development situations, demonstrated by the Cynefin platform. 


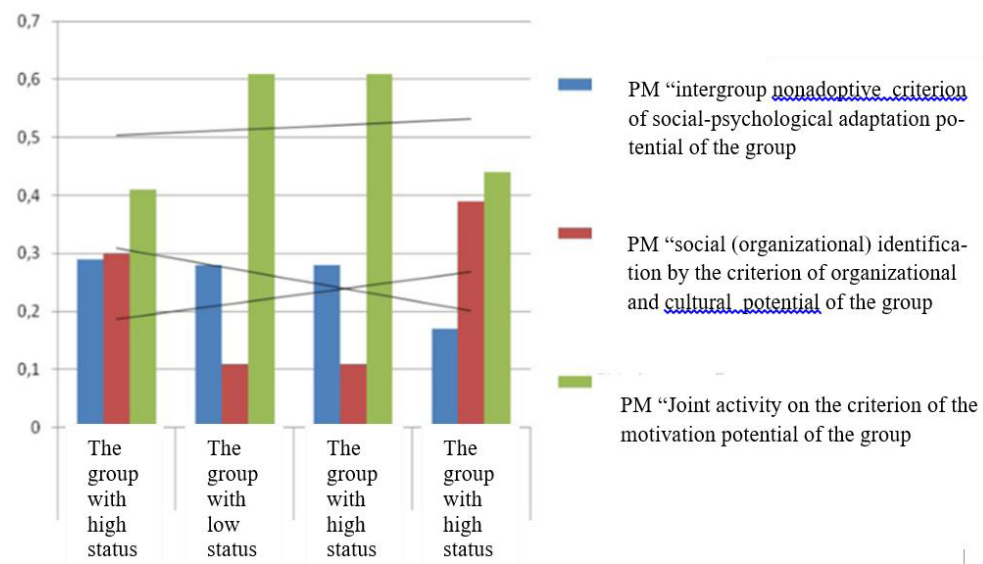

Fig. 2. The motivation potential of the groups (the psychological mechanism of joint activities) as the dominant psychological mechanism of intergroup adaptation, based on the Cynefin platform, designed by D. Snowden ( $\mathrm{n}=40$ individuals).

As for the Order situation, here no assistance from an organizational psychologist is needed. The executive acts under the principle of "setting management priorities." [11]

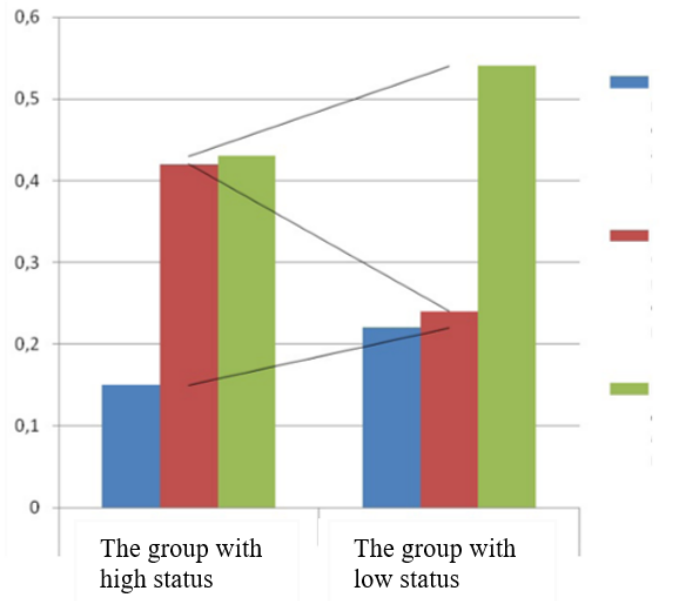

PM “intergroup nonadoptive criterion of social-psychological adaptation potential of the group

PM "social (organizational) identification by the criterion of organizational and cultural potential of the group

PM "Joint activity on the criterion of the motivation potential of the group

Fig. 3. The organizational potential of the groups (the psychological mechanism for organizational identification) as the dominant psychological mechanism for intergroup adaptation in the management situation entitled "Regularity", based on the Cynefin platform, designed by D. Snowden ( $\mathrm{n}=30$ individuals).

The Regularity situation helps an organizational psychologist to compile the programme, designated for the development of corporate culture. The executive is driven by the principle that reads as "identifying the problem, analyzing its importance, setting the priorities to complete the task." 


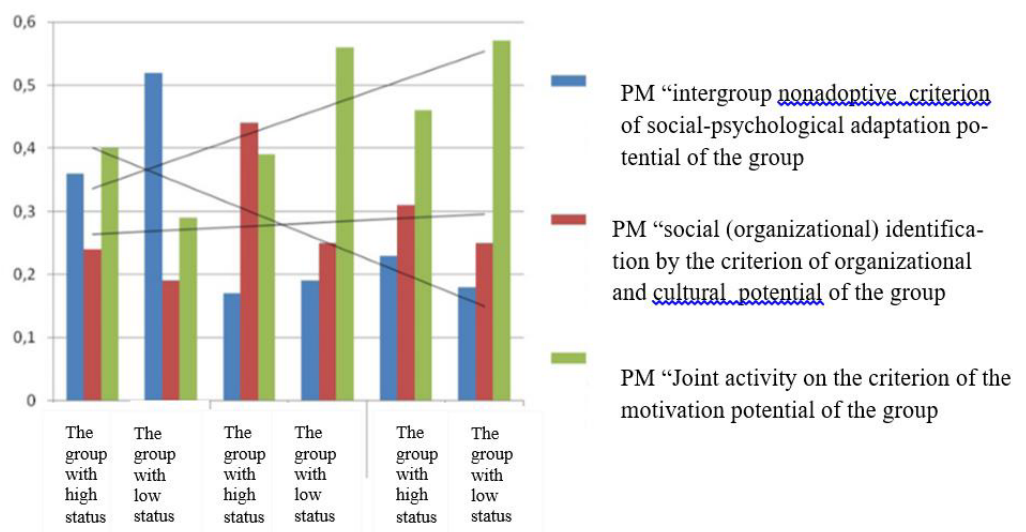

Fig. 4. The adaptive potential of the groups (the psychological mechanism for the intergroup inadaptability) as the dominant psychological mechanism of intergroup adaptation in the management situation entitled "Complexity", based on the Cynefin platform, designed by D. Snowden ( $\mathrm{n}=70$ individuals).

The Complexity situation is tricky due to the unavailability of any standard solutions. The executive is driven by the "experiment" principle. An organizational psychologist should know that in a complex management situation, the alteration of one factor may cause inadaptability. High professional motivation of the groups should be taken into account.

\section{Conclusion}

Motivation potential produces an enormous impact on the production process at construction companies. Attention should be driven to the combination of positive and negative motivation factors, typical for corporate entities. It is necessary to remember that by getting adjusted to varied situations, group members change the motivation potential of their groups and cause the need for other groups, interacting with theirs, to adjust to the new conditions of social interaction. Therefore, the gap between the motivation potentials of interacting groups may cause resonance, leading to constructive solutions. The empiric studies of the Chaos and Uncertainty situations, demonstrated by the Cynefin platform, have generated no findings. In the D. Snowden's theory, no links between cause and effect are identified in the Chaos situation.

The new corporate management instrument is offered in the article. It contemplates the employment of psychological mechanisms for intergroup adaptation as the purposefully employed management resource.

\section{References}

1. T.U. Bazarov, T.U. Konyaeva, Organizational psychology, 2, $43-57$ (2012)

2. A.V. Bulgakov, Bulletin of Moscow State Open University. A series of "Psychological Science", 3, 13-21 (2012)

3. A.V. Bulgakov, E.V. Mitasova, Academy of Military Sciences, 2, 77 - 89 (2005) 
4. A.V. Bulgakov, L.N. Aksenovskaya, Bulletin of Moscow State Open University. A series of "Psychological Science" (2008)

5. D.B. Belinskaya, E.A. Antonova, E.S. Zaitseva, Vestnik of University of Moscow Russian Ministry of Internal Affairs, 6, 205-210 (2016)

6. D.Snowden, Har. Bus. Rev. 12, 50-58 (2007)

7. I.P. Pryadko, Kazan science, 8, 83-85 (2014)

8. N.G. Miloradova, A.D. Ishkov, Advanced Materials Research, 1065-1069, 2538-2541 (2015)

9. C. Rogers, R. Diamond, Psychotherapy and personality change: coordinated research studies and client-centered approach, (University of Chicago, 1954)

10. N.G.Miloradova, A.D. Ishkov, MATEC, 73, 07003 (2016)

11. L.V.Vlasenko, I.P. Pryadko, Integration, partnership and innovations in the civil engineering science and education, 1, 656 - 660 (2012) 